Cite as: Zahl, S. B. (2015). The impact of community for part-time doctoral students: How relationships in the academic department affect student persistence. International Journal of Doctoral Studies, 10, 301-321. Retrieved from http://ijds.org/Volume10/IJDSv10p301-321Zahl0672.pdf

\title{
The Impact of Community for Part-Time Doctoral Students: How Relationships in the Academic Department Affect Student Persistence
}

\author{
Sarah B. Zahl \\ Marian University, Indianapolis, Indiana, USA
}

szahl@marian.edu

\begin{abstract}
This study examines the ways that part-time Ph.D. students develop community within the academic department and how a sense of community is related to persistence. This study included 12 participants (ten students and two program chairs) in two academic departments at one urban research institution. This qualitative study followed a descriptive case study design and provided three levels of data: the institution is the bounded system; the academic departments are the cases; and the participants are embedded cases. Positive relationships with peers and faculty served as a source of encouragement and supported persistence, particularly during challenging semesters and later phases of the doctoral program. However, it was often difficult for the participants to develop and/or maintain relationships, due to limited proximity, limited access to faculty, and changing cohorts. Participants did not consider full-time doctoral students to be part of their community, due to perceived differences between part-time and full-time students. The participants also perceived that faculty catered to full-time students and preferred to conduct research with them rather than part-time students.
\end{abstract}

Keywords: doctoral education, part-time Ph.D. students, community, graduate study, persistence

\section{Introduction}

Projections of the number of doctoral students who leave their programs range from 30 to $70 \%$ (Berelson, 1960; Council of Graduate Schools [CGS], 2008; Hawley, 2010; Lovitts, 2001; Nettles \& Millett, 2006; Tinto, 1993). Despite many national programs (e.g., Carnegie Foundation for the Advancement of Teaching, 2008; CGS, 2008; Woodrow Wilson National Fellowship Foundation, 2005) and institutional efforts to decrease attrition of doctoral students, there has been little to no change in attrition rates in the past 50 years (Berelson, 1960; CGS, 2008).

Pursuing a $\mathrm{Ph} . \mathrm{D}$. as a full-time student is correlated with persistence and degree attainment (Clewell, 1987; Girves \& Wemmerus, 1988; Nettles \& Millett, 2006; Ott \& Markewich, 1985

Material published as part of this publication, either on-line or in print, is copyrighted by the Informing Science Institute. Permission to make digital or paper copy of part or all of these works for personal or classroom use is granted without fee provided that the copies are not made or distributed for profit or commercial advantage AND that copies 1) bear this notice in full and 2) give the full citation on the first page. It is permissible to abstract these works so long as credit is given. To copy in all other cases or to republish or to post on a server or to redistribute to lists requires specific permission and payment of a fee. Contact Publisher@,InformingScience.org to request redistribution permission. because full-time students have more opportunities to interact with faculty and peers. However, the number of parttime students pursuing doctoral degrees continues to grow. According to the Council of Graduate Schools, approximately $33 \%$ of all Ph.D. students in the United States are enrolled part-time, with some disciplines reporting numbers as high as $57 \%$ (CGS, 2012). Despite these percentages, part-time students are 
Impact of Community for Part-Time Doctoral Students

rarely included in the literature on the doctoral student experience (Berelson, 1960; Golde, 1998, 2005; Hawley, 2010; Lovitts, 2001; Lovitts \& Nelson, 2000; Tinto, 1993; Weidman, Twale, \& Stein, 2001; White \& Nonnamaker, 2008).

The increasing numbers of part-time doctoral students combined with attrition rates of up to $70 \%$ (Berelson, 1960; CGS, 2008; Hawley, 2010; Lovitts, 2001; Nettles \& Millett, 2006; Tinto, 1993), warrant special attention on this population of doctoral students. A line of research that holds promise to improve attrition rates revolves around a sense of community between the student and the academic department. Accordingly, this study examined the ways that part-time Ph.D. students develop community within the academic department and how a sense of community is related to student persistence. Specifically, this study investigated two questions: 1) In what ways do part-time doctoral students develop a sense of community within their academic departments? and 2) How does a sense of community influence the persistence of part-time doctoral students?

\section{Literature Review}

Many researchers have found a strong link between attrition and a lack of community between the student and the department of study (Antony, 2002; Lovitts, 2001; Lovitts \& Nelson, 2000). A lack of interaction with faculty and peers can lead to a graduate student experience characterized by loneliness, stress, isolation, and confusion (Gardner, 2008; Hadjioannou, Shelton, Fu, \& Dhanarattigannon, 2007; Lovitts \& Nelson, 2001; Weidman et al., 2001). However, frequent positive interactions produce strong connections to the department and create a system of supportive relationships (Weidman et al., 2001). Research indicates that the highest attrition rates are found in the humanities and social sciences (average ten year attrition rate of 32\% (CGS, 2008)), where programs of study are typically individualized and students are expected to conduct research independently. Conversely, the lowest attrition rates are in the sciences (average ten year attrition rate of $26.2 \%$ (CGS, 2008)), where students are often required to conduct collaborative research and meet regularly with laboratory groups (Baird, 1990; Deem \& Brehony, 2000; Lovitts \& Nelson, 2000; Nettles \& Millett, 2006).

\section{Defining Doctoral Student Community}

Community in educational contexts is frequently associated with foundational ideas of belonging and mattering as they relate to meaningful relationships with others and becoming a valued member of a sustained, collective group (Tinto, 1993; Wenger, 1998; White \& Nonnamaker, 2008). For this study, community is defined as the development of social networks through relationships in the academic setting. Kadushin (2004) defines social networks as relationships that one can draw upon as resources during graduate study. Social relationships with faculty and peers serve as important resources to assist students in working through social, emotional, and academic problems they are likely to encounter while pursuing the doctorate (Golde, 1998, 2005; Hawley, 2010; Lovitts, 2001; Lovitts \& Nelson, 2000; Tinto, 1993; White \& Nonnamaker, 2008).

\section{Tinto's Theory of Doctoral Student Persistence}

Tinto's (1993) book on student attrition includes a foundational model of doctoral student persistence and describes community during doctoral study. While Tinto did not intend to explain the development of community, this research provides a foundational lens to view social and academic systems (the department) as the student's primary community throughout graduate study. Tinto's model proposes that doctoral student persistence depends on how individuals function within social and academic systems. The extent and quality of the interactions in these systems determine the degree to which doctoral students become integrated and ultimately persist to complete the program. One criticism of Tinto's model and other models of doctoral student persistence and socialization (e.g., Weidman et al., 2001) is that all students are assumed to fit the 
model in the same way (Golde, 2000). This "one size fits all" approach fails to address the needs and experiences of certain groups of students, particularly part-time students.

\section{Socialization and Integration into Program Culture}

Socialization is widely accepted as a framework to describe the experiences and development of doctoral students during graduate study (Antony, 2002; Austin, 2010; Gardner, 2007; Golde, 1998, 2000; Weidman et al., 2001). The four-stage model of doctoral student socialization (Weidman et al., 2001) points to the significance of community during doctoral study by emphasizing program culture and the development of supportive relationships with peers and faculty in the department. The foundation of this model is that graduate students experience a developmental metamorphosis that is often accompanied by discomfort, insecurity, and uncertainty. While acquiring new information and accepting the role of doctoral student, individuals proceed through four interactive stages (anticipatory, formal, informal, and personal) of socialization. In order to advance through all four stages students must cultivate and maintain strong networks to provide academic, social, and emotional support throughout graduate study.

The academic department is the environment where community begins for doctoral students since the majority of their interactions take place there (Berelson, 1960; Gardner, 2007; Tinto, 1993; White \& Nonnamaker, 2008). This is particularly true for part-time students who typically do not spend much time on campus, other than class meetings and activities. The extent of a student's integration, or fit, into the social and academic culture in a department is strongly connected to persistence and the quality of the doctoral student experience (Gardner, 2008; Hall \& Burns, 2009; Hawley, 2010; Lovitts, 2001; Tinto, 1993; Watts, 2008). As students recognize commonalities and experience engagement with faculty and peers, they develop a sense of joining and integrating into a large supportive intellectual community (Jazvac-Martek, 2009).

\section{Relationships with Faculty}

Researchers consistently indicate that regular interaction with faculty advisors and mentors is a strong predictor of doctoral student satisfaction, persistence, and productivity (Golde, 1998, 2005; Lovitts \& Nelson, 2000; Spaulding \& Rockinson, 2012; Tinto, 1993; White \& Nonnamaker, 2008). In fact, Lovitts (2001) found that a student's relationship with an advisor is "probably the single most critical factor in determining who stays and who leaves" (p. 270). The amount of time spent, frequency of the interactions, trust, and a sense of care from an advisor are crucial to student success and satisfaction (Austin, 2010; Barnes, Williams, \& Archer, 2010; Golde, 2000; Lovitts, 2001).

Most of the recent literature on the doctoral student experience differentiates between faculty advisors and faculty mentors as these can be two very distinct roles (Golde, 2005; Nettles \& Millett, 2006; Weidman et al., 2001). Advisors are usually formally assigned by the academic department to approve coursework, whereas mentors are typically selected based on interests or personality similarities and are often "faculty to whom students turn for advice...or for general support and encouragement" (Nettles \& Millett, 2006, p. 98). For part-time students, a faculty advisor and/or mentor may be the only departmental connection since they do not spend much time in their departments outside of required classroom attendance (Deem \& Brehony, 2000).

\section{Relationships with Peers}

Interactions with peers are just as important as interactions with faculty in facilitating doctoral student success (Gardner, 2007, 2008; Golde, 1998, 2000, 2005; Lovitts \& Nelson, 2000; Tinto, 1993; Weidman et al., 2001; White \& Nonnamaker, 2008). Interactions with peers shape a student's community during doctoral study by providing support, challenge, mentoring, and ac- 
countability (Gardner, 2007; Jairam \& Kahl, 2012; Weidman et al., 2001). Peer interactions also blend social and academic components, whereas faculty relationships can often be strictly academic in nature (Golde, 2000). Students who are not connected to their social peer community in the department often consider leaving their program because they feel they are missing a significant piece of the overall doctoral student experience (Gardner, 2008; Golde, 2000; Lovitts, 2001). Many part-time students experience difficulty creating and maintaining peer relationships from one semester to the next due to academic demands and balancing other commitments in their lives (Austin et al., 2009; Smith, 2000). For these part-time doctoral students, consistent peer relationships can make a significant difference in the decision to persist through the program.

This study fills two significant gaps in the literature. First, this is one of very few studies focused entirely on part-time Ph.D. students. Second, the existing literature indicates that the development of community during doctoral study is important to student persistence and overall program satisfaction. However, existing studies do not address how doctoral students develop community. The present study fills this gap by investigating the process of relationship development and a sense of community with faculty and peers in the academic department.

\section{Methods}

This research study followed a descriptive case study design (Merriam, 2009; Stake, 2003) with embedded subcases and multiple units of analysis (Yin, 2012). Case studies investigate a particular phenomenon within a specific context, particularly when it is difficult to separate the phenomenon's variables from the environment (Merriam, 2009). Semi-structured interviews (60-90 minutes) were conducted with ten part-time Ph.D. (research based) students from two departments (four from Nursing and six from Education) at one urban research institution. Focusing the sample to a single institution followed the case study design of investigating a phenomenon within a single, bounded system (Merriam, 2009; Stake, 2003) and controlled for differences based on institutional type (Golde \& Dore, 2001). This case study provided three levels of data: the institution is the bounded system; each department is an embedded case; and each student is an embedded case within each department.

At the institution where this study was conducted, full-time graduate study is defined as eight or more credit hours in a semester and part-time is defined as enrollment in fewer than eight credit hours. These guidelines led to the definition of part-time enrollment for this study: a doctoral student enrolled in less than eight credit hours. The students were at or near the qualifying examination phase of their program in order to participate in this study (they were allowed to have up to two courses remaining). Limiting the sample to students at the qualifying examination phase provided data regarding their persistence in their programs and controlled for differences based on current stage in the program. Department Chairs in Nursing and Education sent a study notification to all part-time Ph.D. students who matched the criteria. However, the Department Chairs only facilitated the contact; they did not know which students actually participated. The identity of potential research participants was not revealed to the researcher unless the students contacted the researcher after receiving the notification from the Department Chair. To ensure that students met the criteria of the study, individuals who contacted the researcher were screened via telephone prior to arranging an interview.

The department heads (Department Chair or Graduate Program Chair) from both cases were interviewed (see Appendix A) prior to the student interviews (see Appendix B) to provide context and information about departmental culture, norms, and values. While this study included 12 interviews, the two interviews from department heads were used for context only. Including two departments in this study provided data for comparisons between the cases and led to a set of implications and recommendations for administrators, faculty, and students in both departments. A 
sample size of ten students provided sufficient rich, descriptive data because of the longer indepth interviews with the participants. Sample sizes for many of the qualitative studies that informed this study ranged from three to12 participants (Austin et al., 2007; Golde, 2000; JazvacMartek, 2009) so the sample size of ten students is in line with standards in the field.

Transcriptions of interviews were continuously reviewed for emerging themes and data were grouped into categories for each theme using open coding, axial coding, and then selective coding (Corbin \& Strauss, 2007) and entered into the NVivo qualitative software database. After themes were identified and developed, they were linked to form empirical conclusions. Inductive analysis during data collection ensured that a point of saturation had been reached.

\section{Trustworthiness}

Respondent validation ensured that participants' responses were captured accurately and that interpretation of the data was free of bias (Merriam, 2009; Rossman \& Rallis, 2003).

Participants reviewed interview summaries from their own interviews to provide feedback on emerging findings and verify that the interpretation of the interview and the representation of their stories were correct. Additionally, the findings from the field notes and document analysis were cross-checked with conclusions from the interviews.

To protect the identities of participants, pseudonyms are used for the students and the institution. Approval of this study was obtained from the Institutional Review Board before the participants were secured.

\section{Limitations}

This was a case study of part-time Ph.D. students in two academic departments at a single institution. While the smaller sample size and in-depth interviews provided rich descriptive data that is transferable (Lincoln \& Guba, 1985) and can be extrapolated (Merriam, 2009), part-time $\mathrm{Ph}$.D. students at other types of institutions may have different experiences than those represented in this study. Utilizing Department Chairs to help identify potential participants may also be a limitation. In some cases, the Department Chairs may have had close relationships with certain students, which could have made students feel that they must participate in the study. However, students were anonymous participants and department chairs did not know who participated and who did not, so this was in fact a voluntary study. Additionally, the Nursing program included a combination of face-to-face and online courses. Some of the issues related to proximity and limited community articulated by students in the Nursing sample were due to this hybrid program structure and may not apply to traditional classroom environments. Since this study includes two disciplines, differences in academic culture may affect the results. Conducting the study within one institution helped control these differences, but departmental characteristics play a role in one's sense of community. Lastly, some of the participants had limited familiarity with the researcher due to previous interactions at the institution used for the study.

\section{Results}

Three major themes emerged in the data: (a) the ways that part-time doctoral students define a sense of community within academic departments, (b) the impact of relationships with peers, and (c) the impact of relationships with faculty.

\section{What is Community for Part-time Ph.D. Students?}

Participants discussed several concepts of community: feeling connected to the academic department, a sense of belonging and trust, scholarly community of practice, and relationships with peers and faculty. The concepts presented in this section are multi-faceted and are discussed in 
more detail throughout this article, but they are presented here to provide context to the meaning of community for the participants in this study.

\section{Feeling connected to the academic department}

All of the participants indicated that developing a sense of community must involve feeling connected to the academic department. Their connections largely involved forming relationships with peers and faculty, but some students also described connectedness simply based on the culture of the academic environment. Interactions with other people are the key element in most descriptions of academic culture (Gardner, 2008; Hall \& Burns, 2009; Hawley, 2010; Lovitts, 2001; Tinto, 1993; Watts, 2008). However, in some ways, participants' descriptions of connections based on the culture did not necessarily involve having a relationship with persons in the department, but stemmed from general feelings of a supportive space. For example, many students described a community as a place where "it feels like you are not alone" or "an informal culture that tells me there is community." These descriptions involved people, but did not necessarily involve knowing those people on a personal level. These statements suggest that the participants would know there is a community simply by walking through a space and observing the way that others behave there.

\section{Sense of belonging}

A sense of belonging was described as feeling valued and appreciated by others in the community, developing mutual trust and encouragement, and knowing that you genuinely matter to someone else. Henry, a part-time doctoral student in Education, described a sense of belonging in this way: "It feels like you have a group of people that empathize with you. They understand the struggles of finishing your doctorate which includes some, you know, self-doubt, fatigue, all that stuff. They can encourage you; you encourage each other." Other participants noted that a sense of belonging stems from finding a common purpose, developing mutual respect, and feeling that "we are all in this together" and "part of a team."

\section{Scholarly community of practice}

Over half of the participants described a sense of community in the academic department as a scholarly community of practice (Wenger, 1998). Wenger's definition of a scholarly community of practice includes learning together, relying on each other, and sharing similar values and goals. Students conceptualized this as an open environment where people of similar values and beliefs around a certain topic or field gather to collaborate with other scholars and share ideas related to research and practice. The participants indicated that there are significant structural barriers for part-time students that limit scholarly engagement, but the scholarly community of practice served as a resource to help them overcome those barriers. Jacob referred to this when he stated,

Some of the parameters of our program fracture us slightly, but I still think that the ability for us to rally together on important issues in higher education brings us together. It's a group of peers coming together, or a community of learners or scholars coming together to better the field and the profession. I think my desire to do the work that I do got further fueled by being here and being in the presence of these people.

This subtheme is multifaceted in both cases: some of the participants described themselves as a member of a scholarly community of practice; others noted that this type of community was absent in their own academic department; and two participants described it as something they experienced only at certain points during their program. The participants who focused on scholarly interactions with faculty described an inconsistent or absent scholarly community of practice. Conversely, those who focused on scholarly discussions with peers (rather than faculty) described themselves as members of a scholarly community of practice throughout their program of study. 
Notably, all of the students who explained this as an absence attributed it to their status as a parttime doctoral student; they described it as a characteristic of doctoral study that only applies to the full-time student experience.

\section{Relationships with Peers}

When describing interactions during doctoral study, the participants articulated clear differences between peers and faculty. Connections with other students played a role in many different environments - in the classroom, in informal learning spaces, in social settings, and in professional environments (conferences and work). Notably, almost all of the participants interacted with their academic peers in their career settings as well, so they knew their peers as professional colleagues as well as peers in their academic program. This phenomenon was viewed both positively and negatively by the participants because it was often difficult to manage both of these roles simultaneously within the same environment.

\section{Support and understanding}

Every participant discussed the importance of peer relationships and described their peers as one of the reasons for their persistence in their programs. All of the students experienced a stronger sense of community with other part-time students because they could understand the unique circumstances they encountered due to their student status. Megan described her part-time peers as a support network:

It was really important to me in terms of balance and being productive to find confidants in the program. Particularly building a relationship with...those folks that were in my [professional seminar] group because I knew that there were others that were dealing with some similar challenges. And sometimes it was really helpful just to say to someone, 'it is really frustrating that I have all of this to do and not enough time to do it in.'

Peers served as personal and academic resources and provided encouragement to overcome challenges they encountered during doctoral study. In fact, most participants indicated that they "wouldn't have known what to do" in certain courses or at specific points in the program, had they not been able to rely on their peers as a source of information. For example, several Nursing students had to repeat a specific course in the program and relied on peers for support during this challenging process. In every case, the students cited peer support and encouragement as the reason they successfully completed the course and developed a strong sense of community with their peers as a result of working through this challenge together. Caroline described the way that her peers encouraged her to persist in her program:

I don't think you would want to get to that end goal unless you had had those relationships and had that time together. Because I could see that without that I probably would not have been able to get through some of the harder times.

Peer relationships mattered even more in the later stages of the doctoral program as students were nearing the end of coursework and preparing for the qualifying examination. The students who had finished coursework noted that, due to the independent nature of qualifying examinations, they had not interacted with their peers as much as they did when they were in classes together. As a result, they felt more isolated during a time when they needed significant guidance and support, which led to a weaker sense of community with their peers during this phase of doctoral study. However, when a peer made an effort to reach out to another student individually during this time, those efforts had a significant positive impact on one's sense of community. The results of this study suggest that, during periods of loneliness or isolation, the supportive actions of just one peer can create a sense of community not only with that individual, but with the broader academic community as well. 
When support is removed. Two students described specific points in their program when they felt a lack of peer support and an absence of community. In both situations, they had already established strong peer relationships, but specific circumstances challenged those relationships. Their stories are particularly poignant because they illustrate how painful separation from peers can be for a part-time doctoral student. Cynthia began the program with a cohort of seven Ph.D. students, but the cohort shrank to only three people. When each person dropped from the program, it had a detrimental effect on her relationships as well as her faith in her own ability to complete the program. She described a specific moment when one of her peers told her that she was leaving the program:

When she emailed us and told us she was quitting I just remember thinking 'oh man I don't know if I can continue'...so each time I think that that has an impact on you because your support is getting smaller and smaller.

Diane described a specific semester when she felt isolated from her peers because she did not have the minimum number of hours required to take a capstone course with the rest of her cohort. She described feeling left out and missing an opportunity to reflect on the program with the peers she had relationships with since the beginning of her program:

I was excluded from taking that class. So most of my cohort took that class together, and being that it did have an education piece to it, there was a lot of reflection. I wasn't getting to participate in a class with a group that I have been with and that next summer when I get to take it, because it is only offered in the summer, I won't be in a class with people that I have known all along.

Because she missed the course, she had to take it the following year with a different group of students. These two examples illustrate the negative consequences of feeling removed from peers after developing strong connections to them as part of an academic community. Diane and Cynthia felt completely removed from the peer community they had developed over time. In Cynthia's case, she began to doubt herself and her abilities to persist in the program each time another one of her peers dropped out. These stories suggest that losing members of one's peer community can have a negative impact on a student's rate of persistence in the program because the student's departmental connections are reduced.

\section{Difficult to develop peer relationships}

Nine of the ten participants described the process of creating and/or maintaining peer relationships as very difficult due to perceived differences in levels of commitment/experience, changing cohorts, and limited proximity.

Differences in level of commitment/experience. Many of the students found it difficult to engage in scholarly discussions with peers due to differences in the level of commitment between themselves and their peers. Students noted that they were drawn to certain peers in the program because they had similar purposes for pursuing the Ph.D. and they were committed to maintaining a similar high level of quality in discussions and assignments. Eric recalled that the perceived lower level of commitment from his full-time peers was very surprising because he was often envious of those who attended full-time. He said, "Even with this opportunity of being supported or going full-time, which I would have preferred to have done, they just, not all of them seemed to be as committed as I was, which was kind of a shock."

Participants attributed a higher level of commitment for part-time students to differences in age and years of prior work experience, specifically having at least a few years of work experience between the masters and the doctorate. Megan attributed her success in the program to finding and socializing with peers who "have a similar approach to work" as she does because they are 
reliable and maintain a level of rigor in their courses. She noted that the variance in commitment level due to age and/or professional experience often divides students:

I think that sometimes it creates tension between the students, right? There is no 'good enough' in my world. And I feel sometimes, maybe it is about age too. That some of the younger students in the program that tend to be the full-time students are not perhaps as rigorous in their work.

These differences affected how the participants perceived their peers and who they considered part of their academic community. They developed a stronger sense of community with their peers who were similar to them in age, professional experience, and approach to coursework. In addition to the dichotomy between full-time and part-time students, Megan made a distinction between her peers who were "doers" and those who were "thinkers." The "doers" tended to focus more on the applied portions of the program and were obtaining a credential, while the "thinkers" were those who were more theoretical or wanted to conduct research. She noted that the "research versus applied" dichotomy can create tensions when doing group work or having discussions in class because students tend to identify with either the "doers" or the "thinkers," but typically not both. These distinctions have significant implications for the development of community with peers. If "doers" and "thinkers" identify and interact primarily with others who are like them, students are likely to experience community in pockets rather than widespread community with all of their peers. This finding also presents an interesting tension regarding the lack of consensus around the role of part-time doctoral students. Many see them as solely focused on practice, yet some of the participants in this study pursued the doctorate because they aspired to research or faculty careers. Another way to view this tension is through the lens of research (i.e., "thinker") and applied practice (i.e., "doer").

Changing cohorts. Almost half of the participants found it difficult to connect and develop community with their peers because they lost track of their cohort during the program. Because of the pace in which they enrolled in courses as part-time students, they began their Ph.D. with a certain cohort, but eventually ended their coursework with an entirely different group of students. Participants expressed concerns about not seeing anyone from their original cohort after their first year and noticing that their full-time peers got "way ahead" of the part-time students. One student described shifting among multiple cohorts and noticing that all of the other students from his original cohort were already finished with the program:

I have had like 2 or 3 different cohorts since I have been here, the original and then maybe the folks that started a year, maybe a year after I did and then there was another one that started a little further beyond that. That first cohort, most of them have actually finished.

The participants who shifted between cohorts were attempting to develop several different peer communities rather than one large peer community. The challenge of assimilating into multiple peer groups increases the difficulty of developing a general sense of community within the academic department.

Proximity. Almost all of the participants described difficulties connecting with peers due to limited proximity (time, place, or occurrence). The Education participants noted that they interacted with peers regularly during class meetings, but it was very rare to interact with them outside of the traditional classroom environment due to their part-time status. The classroom environment was structured to include peer interaction through group work, peer feedback, and organized class discussions. Outside of those required interactions, it was rare for the students to interact with each other except for seeing each other occasionally in passing. Henry noted this when he stated,

Inside the classroom it's, I mean, I think we are a lot closer. I mean just because of the nature...We like to share our opinions and all that other stuff so that was never a problem. But unless it was someone in 
the class that I knew personally, once we left that classroom that was pretty much it as far as correspondence and engagement.

Since all of the participants worked full-time, they did not have the opportunities to engage in the same social activities that full-time students did. The Nursing participants described a sense of community during the structured summer intensive sessions, but noted a lack of connection with peers during the rest of their educational experience.

\section{Relationships with Faculty}

Interactions with faculty were described as very different from peer relationships for many reasons, but primarily because peers were described as "equals" or "colleagues" while faculty were described as mentors to "look up to," or senior scholars that students were "in awe of" due to their accomplishments. In all cases, faculty members were viewed as knowledgeable, experienced scholars who had the potential to serve as resources for the students.

\section{Support via advising/mentoring}

All of the participants described a supportive relationship with at least one faculty member during their doctoral program. Faculty members were described as "encouraging," "understanding," and "very dedicated" to their work in the field and helping students succeed. Many of the participants specifically mentioned their primary advisor/program chair as a fairly consistent form of support. However, for most of the participants, a specific faculty member who was not the assigned advisor served as their greatest advocate. Notably, four of the Education participants mentioned the same faculty member as their biggest source of support, specifically because she was a known advocate for part-time students. One of the participants described feeling supported by this particular faculty mentor because she was "...very willing to meet you where you are regardless of your family situation or maybe just taking that into context: taking into context your family situation, taking into context your individual interests as a student." It was evident that the participants had a stronger connection with the faculty member they identified as a mentor; it was almost as if they took pride in choosing that person as a mentor and made additional efforts to develop community with him/her. Relationships with mentors also supported accountability and persistence.

\section{Difficult to develop faculty relationships}

Participants pointed to the difficulties of developing and maintaining relationships with faculty members. Students cited various reasons for this lack of connection with faculty, but concepts that came up consistently were limited availability and proximity, catering to full-time students, and a lack of research opportunities.

Faculty unavailable. Developing relationships and community with faculty was challenging because faculty were often not available to provide support, have conversations, or even respond to email requests. This was a considerable disappointment and quite different from their original expectations of their doctoral program. Henry illustrated that he was surprised by the lack of interactions between students and faculty because he expected a more collegial environment:

It doesn't seem as collegial as I thought it would be. I always envisioned folks just kind of sitting around in the middle of the room or the middle of the floor discussing this or discussing that and collaborating in that way. It seems like a lot of people are in their offices doing their own thing. So I don't necessarily feel as connected.

The participants acknowledged that faculty members were very busy and had "more important" things to do and projects to manage. However, it became evident that this was a point of frustration for the students. Interestingly, the participants often described immense respect and awe to- 
ward their faculty members in regards to their research and service, but faculty commitment to their scholarly work also led to feelings of disconnection and frustration for the students. For example, Rebecca explained that she would have felt a stronger sense of community in her program "if professors weren't so busy and weren't out there saving the world" instead of being present and available to students.

Faculty cater to full time students. Some of the participants noted that faculty members made themselves more available to full-time students, and therefore were not accessible to the parttime students. There was a sense that faculty preferred to work with full-time students because they assumed they were more committed, would finish the program faster, and needed/wanted more opportunities to interact with faculty. Further, the students perceived that faculty catered to full-time students because they had more free time on campus and could just "drop in" to faculty offices, attend presentations, and interact with faculty socially. Eric said, "Because I am parttime, I don't expect to be catered to. You know, I am not the primary or the most preferred constituency in terms of doctoral students...But, half time is not only half effort." Cynthia concluded that faculty members cater to full-time students because they are more likely to enter academia after they complete the program:

I think there is an assumption that, as a part-time student, you are not going to be in academia and you are so busy with your career that, I don't think they intentionally do it, but they focus on the people that are going to replace them someday in the future. So the students with academic potential, I think, get more attention if you will and get a different program than what I have. As far as actual coursework we are getting the same things, but it is the extra learning experiences and opportunities that are not the same.

The perception that faculty were unavailable or preferred to work with full-time students negatively impacted the participants' sense of community because the students did not feel that they mattered as much as the full-time students.

Proximity. A lack of proximity made it challenging to develop relationships and community with faculty. The students interacted with faculty regularly during classes, but it was very rare to interact with them outside of the traditional classroom environment. Further, the participants rarely spoke with faculty before or after class regarding topics unrelated to the course curriculum (e.g., research opportunities, social conversations, etc.). Interactions had to be formalized and planned in advance because the part-time students did not have the luxury of the "stronger and closer access to faculty" as did full-time students. Eric, an Education student, noted that faculty may not consider the needs of part-time students as much due to the "out of sight, out of mind" phenomenon. Interestingly, three additional Education students described similar concerns of feeling removed and even overlooked by the faculty due to their part-time status. I asked the Education Program Chair about part-time students' interactions with faculty and how proximity affects access to faculty. The Chair noted,

At the doctoral level, this is about making your own experience, making your own way. There are students here... who take the initiative to get to know and get some experiences with the faculty members that are around. Faculty members aren't doing things too actively to, kind of, make sure everybody is getting equal time. We're waiting for others to take the initiative; we're not doing a lot of the initiative on our own due to schedules and busyness.

This comment suggests that faculty are available to students, as long as the students initiate the connection. However, the students in this study indicated that they had been intentional about trying to connect with faculty, but still felt removed from them. This dichotomy indicates that differences in expectations between the students and program faculty can hinder the development of community and affect student persistence. Some of the Education students felt so removed from faculty that they began developing their dissertation research without having a chair or 
committee in place. Ultimately, this delayed their formal dissertation process and affected their rate of persistence.

The participants in Nursing discussed a lack of proximity to faculty, primarily as it relates to mentoring and/or advising. The Program Chair described mentoring and advising as "highly individualized" and "very important for students and faculty in keeping engaged." However, the students perceived discrepancies between how full-time and part-time students were mentored. Full-time students received in-depth, frequent mentoring from multiple faculty members throughout their program, whereas the part-time students received sporadic mentoring, typically from only one faculty member. Cynthia explained, "The full-time students get a lot of intensive mentoring and a lot of interaction with different faculty. Many of the others who are [part-time], are having to find their own opportunities or just trying to get through the program."

Limited access to research opportunities. Formal and informal research opportunities are very important to the doctoral process, particularly as students are transitioning from the role of student to scholar. The participants shared that access to research opportunities was very limited, and attributed these limitations to their status as part-time students. The students described conducting research with faculty as "impossible" due to their part-time status. They indicated that their full-time peers had more opportunities for research with faculty through assistantships, conference presentations, and writing grant applications or articles. Further, the participants noted that faculty often offered research opportunities to the "preferred" full-time students first. Henry said, "We are just not on their radar...I doubt [faculty] would try to identify students from our part-time student pool first." Eric's description of research opportunities for part-time students was very similar:

Full-time doctoral students that are supported through assistantships in the school or in school related units. Those sort of students are certainly, you know, the preferred constituents, the preferred students, because they see them, and because they tend to go through in a timelier manner than part-time students.

Eric indicated that he thought faculty viewed him as "sort of a hanger on out there on the side" since he was a part-time student and did not have opportunities to interact with faculty as much as his full-time peers. It became clear that access to research opportunities supported the development of community, while a lack of access hindered community.

\section{Discussion}

The study participants defined a sense of community as feeling connected to the academic department, a sense of belonging and trust, being part of a scholarly community of practice, and relationships with peers and faculty. These ideas are fairly consistent with previous studies about community during doctoral study, with one exception. Existing research in this area indicates that departmental communities shape the doctoral student experience through academic and social interactions with faculty, peers, and professionals in the field (Golde, 2005; Lovitts, 2001; Tinto, 1993; Weidman et al., 2001). In this study, participants did not mention professionals in the field as members of their community. While their peers were professionals and the students held professional positions themselves, the existing literature focuses on external professionals as part of the academic community. This difference is most likely due to the fact that the previous studies included full-time students only; part-time $\mathrm{Ph} . \mathrm{D}$. students are professionals themselves, and therefore, are exposed to their profession simply by working within it rather than interacting with external professionals through their coursework.

The foundational requirement for developing a sense of community was feeling connected to the academic department. Connections were formed primarily via relationships with peers and faculty, but some students also described connectedness based on the general culture of a supportive 
academic environment, or the way that simply being within the space made them feel. The descriptions involved people, but did not necessarily involve knowing those people on a personal level. This finding adds to the literature on doctoral student community because most of the studies focus specifically on relationships as a means to build connections in the academic department. According to Weidman et al. (2001), students must develop relationships with other people in order to experience strong connections to the department. Interestingly, the participants in the current study described connections based on brief interactions that did not necessarily lead to relationships. Further, some of the participants experienced feelings of connectedness based on observations alone, without interacting with people at all.

\section{Revisiting Tinto's Model of Student Persistence}

Tinto's (1993) model of student persistence proposes that doctoral student persistence is dependent on how individuals become integrated and function within social and academic systems. Tinto's model does not include part-time students and fails to address the unique experiences of this population, particularly as the model relates to a sense of belonging and fit in academic and social systems. Because existing studies focus on the traditional, full-time student experience, researchers often assume that a student moves to a new location to begin the Ph.D. and therefore, needs to develop a new social life in addition to his/her academic life. The present study indicates that academic and social spheres overlap for part-time Ph.D. students. Because of their limited availability to participate in social activities outside of class, part-time doctoral students develop social connections and relationships primarily inside the classroom, while completing academic activities such as group work or projects. Based on the results of the current study, it is clear that academic and social integration is directly correlated with persistence. However, for the part-time $\mathrm{Ph}$.D. students in this study, there is only one integrated system: their academic and social spheres overlap.

\section{Peer Relationships}

Many part-time students experience difficulty creating and maintaining peer relationships from one semester to the next due to academic demands and balancing other commitments in their lives (Austin et al., 2009; Smith, 2000). This was certainly true for the participants in this study; they cited their part-time status as the reason they experienced difficulties connecting with their peers. However, the participants drew a clear distinction between their relationships with their part-time peers and their relationships with full-time peers. Most of the participants found it difficult to relate to and develop connections with their full-time peers, citing differences in level of commitment and professional experience. Previous research indicates that a lack of interaction with peers can lead to loneliness and isolation in the academic department (Gardner, 2008; Hadjioannou et. al, 2007; Lovitts \& Nelson, 2001; Weidman et al., 2001). While the students in this study could relate to their fellow part-time peers, many of them described isolation from their full-time peers. Further, the participants mentioned obvious divisions and/or tensions between the two groups of students. Because of this, they experienced a strong sense of community with their part-time peers, but very limited community with their full-time peers.

\section{Distance education}

Students in distance learning programs may be more likely to experience isolation and/or separation from the academic department because of their lack of proximity to the institution and their peers (Exter, Korkmaz, Harlin, \& Bichelmeyer, 2009; Horn, 1994; Liu, Magjuka, Bonk, \& Lee, 2007; Morgan \& Tam, 1999; Palloff \& Pratt, 1999). This was true for the Nursing participants in the present study, who described difficulties connecting with peers in their online classes. The face to face summer sessions were very structured and included required group work and partner 
Impact of Community for Part-Time Doctoral Students

activities, which supported a sense of community. However, participants struggled to maintain those connections with their peers outside of the required summer intensives.

\section{Faculty Relationships}

Researchers consistently indicate that regular interaction with faculty advisors and mentors is a strong predictor of doctoral student satisfaction and persistence (Golde, 1998, 2005; Lovitts \& Nelson, 2000; Tinto, 1993; White \& Nonnamaker, 2008). Further, Lovitts (2001) suggests that a student's relationship with a faculty advisor is the most important factor in a student's decision to persist or leave the program. While the students in the present study described their primary advisor/program chair as a source of encouragement, almost all of the students (9/10) identified at least one faculty member, other than their advisor, who served as a mentor and/or advocate during their doctoral program. This finding affirms Lovitts' (2001) conclusion that a strong, supportive relationship with a faculty member is critical, but that person may be someone other than the assigned advisor.

\section{Faculty cater to full-time students}

Participants perceived that faculty members made themselves more available to full-time students, and therefore were not accessible to part-time students. There was a sense that faculty preferred to work with full-time students because they assumed they were more committed to the program. The concept of full-time students as "preferred constituents" was present throughout all of the interviews. Differential faculty support is a very significant to the development of community for part-time Ph.D. students.

\section{Comparisons to Doctoral Socialization Model}

Part-time students are not included in existing doctoral socialization models; therefore, it is important to provide some comparisons from this study in order to address this gap in the research. Since doctoral programs prepare students to be professionals in the field, most of the literature combines socialization into the roles of student and professional (Antony, 2002; Austin, 2010; Gardner, 2007; Golde, 1998, 2000; Weidman et al., 2001). The results of the current study refute this assumption. Every participant in this study was already employed full-time in the professional area in which he/she was pursuing the doctorate; the participants had already been socialized into their professional roles in the field prior to beginning the Ph.D. Therefore, the role of doctoral student was a specific role in itself for these part-time students. The results of this study indicate that part-time Ph.D. students experience two distinct socialization processes - socialization into the professional role and socialization into the student role during graduate study. Their socialization processes cannot be lumped together into one general model of doctoral socialization. Thus, part-time Ph.D. students do not fit into the existing socialization frameworks. Researchers (Austin, 2010; Gardner, 2007, 2010) have called for a study that addresses socialization at the degree level and noted that this is a significant gap in the literature. This study addresses this gap by examining socialization exclusively at the student level rather than viewing student and professional socialization as one combined process.

\section{Implications for Practice}

There are several ways that faculty and administrators in academic departments can support the unique needs of this population and cultivate a sense of community.

\section{Include purposeful, supportive interactions with faculty}

The students in this study articulated difficulties accessing faculty and developing relationships with them. Due to the nature of the part-time student experience and balancing multiple life 
roles, doctoral programs need to include purposeful required events and meetings with faculty to foster community.

\section{Provide more equitable research opportunities for part-time students}

This study brought forth evidence of a perception that faculty preferred to conduct research with full-time students rather than part-time students. This concept has major implications for academic programs that accept part-time Ph.D. students. Even if this is a perception rather than a proven fact, the perception alone led to discouragement and frustration, and hindered the development of community with faculty. Academic programs must provide more equitable access to research for part-time and full-time students. For example, adding research projects to topical courses or seminars would provide an opportunity to conduct research with a faculty member.

\section{Plan/revise program structures to accommodate part-time students}

The participants consistently pointed to structural and procedural barriers that impeded their sense of community. First, it is important to consider the timing and rotation of course offerings. Second, it is important for academic programs to consider the implications of the cohort model for part-time Ph.D. students. Since part-time students are taking fewer courses than their full-time peers, they often lose track of their cohort and "start over" with a different group of students each semester. Program administrators could consider creating doctoral cohorts specifically for part-time students only; this structure would allow students to create and maintain connections and community with the same group of students throughout their program.

\section{Emphasize the importance of peer connections}

All of the part-time Ph.D. students in this study articulated the importance of their peers, describing them as a resource and source of support. While some of the students struggled to connect with a tangible community (ongoing interactions and connections through relationships), the ability to be part of a perceived community (a feeling that a community exists based on observations and available resources) was very meaningful and created feelings of a supportive space. Academic departments should consider developing peer mentoring programs or peer support groups to foster the development of community. It is also important to encourage students to participate in graduate student organizations or social groups within the academic department.

\section{Implications for Research}

The results of this study provide a foundational understanding of the ways that part-time Ph.D. students develop community and how a sense of community supports student persistence, but more research is needed to cultivate additional understanding of this population. First, a study of multiple institutions would provide additional data to determine if the themes presented in this study are supported in a larger sample of part-time Ph.D. students in different academic programs at other types of institutions. Second, a comparison study of persisters vs. non-persisters would provide a wealth of information on success factors and challenges within the same institutional framework. Next, the results from this study indicate a need to conduct a large scale study that compares the experiences of part-time and full-time doctoral students. Future research should focus on access to research opportunities and the perception that faculty prefer to work with fulltime students. Lastly, as more doctoral programs offer online courses and/or distance accessible options, it is important to conduct research specifically focused on the doctoral student population. Further, it is necessary to investigate how part-time doctoral students might experience online environments differently from their full-time peers.

As the numbers of part-time Ph.D. students continue to increase, institutions must acknowledge the unique needs of this population. The results of this study indicate that part-time doctoral stu- 
Impact of Community for Part-Time Doctoral Students

dents may struggle to cultivate relationships with peers and faculty. Academic departments can develop intentional academic and social resources for this population in order increase their sense of community and support persistence during doctoral study.

\section{References}

Antony, J. S. (2002). Reexamining doctoral student socialization and professional development: Moving beyond the congruence and assimilation orientation. In J. C. Smart \& W. G. Tierney (Eds.), Higher education: Handbook of theory and research, 17, pp. 349-380. New York, NY: Agathon Press.

Austin, A. E. (2010). Foreword. In S.K. Gardner \& P. Mendoza (Eds.), On becoming a scholar: Socialization and development in doctoral education, pp. xi-xvii. Sterling, VA: Stylus Publishing.

Austin, J., Cameron, T., Glass, M., Kosko, K., Marsh, F., Abdelmagid, R., \& Burge, P. (2009). First semester experiences of professionals transitioning to full-time doctoral study. The College Student Affairs Journal, 27(2), 194-214.

Baird, L. L. (1990). The melancholy of anatomy: The personal and professional development of graduate and professional school students. In J. C. Smart \& W. G. Tierney (Eds.), Higher education: Handbook of theory and research, 17, pp. 361-392. New York, NY: Agathon Press.

Barnes, B. J., Williams, E.A., \& Archer, S. A. (2010). Characteristics that matter most: Doctoral students' perceptions of positive and negative advisor attributes. NACADA Journal, 30(1), 34-46.

Berelson, B. (1960). Graduate education in the United States. New York, NY: McGraw Hill.

Carnegie Foundation for the Advancement of Teaching. (2008). Carnegie Initiative on the Doctorate: Brief overview. Retrieved October 15, 2010 from http://www.carnegiefoundation.org/CID

Clewell, B. C. (1987). Retention of black and Hispanic doctoral students. GRE Board Newsletter, 3(1), 2.

Corbin, J., \& Strauss, A. (2007). Basics of qualitative research: Techniques and procedures for developing grounded theory (3rd ed.). Thousand Oaks, CA: Sage.

Council of Graduate Schools. (2008). Ph.D. completion and attrition: Analysis of baseline program data from the Ph.D. completion project. Washington, DC: Council of Graduate Schools.

Council of Graduate Schools. (2012). Graduate enrollment and degrees: 2001 to 2011. Washington, DC: Council of Graduate Schools.

Deem, R., \& Brehony, K. J. (2000). Doctoral students' access to research cultures - Are some more unequal than others? Studies in Higher Education, 25(2), 149-165.

Exter, M. E., Korkmaz. N., Harlin, N. M., \& Bichelmeyer, B. A. (2009). Sense of community within a fully online program: Perspectives of graduate students. Quarterly Review of Distance Education, 10(2), 177-194.

Gardner, S. K. (2007). "I heard it through the grapevine": Doctoral student socialization in chemistry and history. Higher Education, 54, 723-740.

Gardner, S. K. (2008). Fitting the mold of graduate school: A qualitative study of socialization in doctoral education. Innovative Higher Education, 33, 125-138.

Girves, J. E., \& Wemmerus, V. (1988). Developing models of graduate student degree progress. Journal of Higher Education, 59, 163-189.

Golde, C. M. (1998). Beginning graduate school: Explaining first year doctoral attrition. In M. S. Anderson (Ed.), The experience of being in graduate school: An exploration, (pp. 55-64). San Francisco, CA: Jossey-Bass.

Golde, C. M. (2000). Should I stay or should I go? Student descriptions of the doctoral attrition process. Review of Higher Education, 23(2), 199-227. 
Golde, C. M. (2005). The role of the department and discipline in doctoral student attrition. Journal of Higher Education, 76(6), 669-700.

Golde, C. M., \& Dore, T. M. (2001). At cross purposes: What the experiences of doctoral students reveal about doctoral education (Report). Philadelphia, PA: Pew Charitable Trusts.

Hadjioannou, X., Shelton, N. R., Fu, D., \& Dhanarattigannon, J. (2007). The road to a doctoral degree: Co-travelers through a perilous passage. College Student Journal, 41(1), 160-178.

Hall, L. A., \& Burns, L. D. (2009). Identity development and mentoring in doctoral education. Harvard Educational Review, 79(1), 49-70.

Hawley, P. (2010). Being bright is not enough: The unwritten rules of doctoral study. Springfield, IL: Thomas Books.

Horn, D. (1994). Distance Education: Is interactivity compromised? Performance and Instruction, 33(9), 12-15.

Jairam, D., \& Kahl, D. H. (2012). Navigating the doctoral experience: The role of social support in successful degree completion. International Journal of Doctoral Studies, 7, 311-328. Retrieved from http://ijds.org/Volume7/IJDSv7p311-329Jairam0369.pdf

Jazvac-Martek, M. (2009). Oscillating role identities: The academic experience of education doctoral students. Innovations in Education and Teaching International, 46(3), 253-264.

Kadushin, C. (2004). Introduction to social network theory. Retrieved September 26, 2010 from http://www.communityanalytics.com/Portals/0/Resource_Library/Social\%20Network\%0TheorT_Kadus $\underline{\text { hin.pdf }}$

Lincoln, Y. S., \& Guba, E. G. (1985). Naturalistic inquiry. Beverly Hills, CA: Sage.

Liu, X., Magjuka, R. J., Bonk, C. J., \& Lee, S. (2007). Does sense of community matter? An examination of participants' perceptions of building learning communities in online courses. Quarterly Review of Distance Education, 8(1), 9-24.

Lovitts, B. E. (2001). Leaving the ivory tower: The causes and consequences of departure from doctoral study. Lanham, MD: Rowman \& Littlefield.

Lovitts, B. E., \& Nelson, C. (2000). The hidden crisis in graduate education: Attrition from Ph.D. programs. Academe, 86, 44-50.

Merriam, S. B. (2009). Qualitative research: A guide to design and implementation. San Francisco, CA: Jossey Bass.

Morgan, C. K., \& Tam, M. (1999). Unraveling the complexities of distance education student attrition. Distance Education, 20(1), 96-108.

Nettles, M. T., \& Millett, C. M. (2006). Three magic letters: Getting to Ph.D. Baltimore, MD: The Johns Hopkins University Press.

Ott, M. D., \& Markewich, T. S. (1985, April). Logit analysis of graduate student retention and graduation. Paper presented at the annual forum of the Association for Institutional Research, Portland, OR.

Palloff, R. M. \& Pratt, K. (1999). Building learning communities in cyberspace. San Francisco: JosseyBass.

Rossman, G. B., \& Rallis, S. F. (2003). Learning in the field: An introduction to qualitative research (2nd ed.). Thousand Oaks, CA: Sage.

Smith, P. R. (2000). A meeting of cultures: Part-time students in an Ed.D program. International Journal of Leadership in Education, 3(4), 359-380.

Spaulding, L. S., \& Rockinson, A. J. (2012). Hearing their voices: Factors doctoral candidates attribute to their persistence. International Journal of Doctoral Studies, 7, 199-219. Retrieved from http://ijds.org/Volume7/IJDSv7p199-219Spaulding334.pdf 
Stake, R. E. (2003). Case studies. In N. K. Denzin \& Y. S. Lincoln (Eds.), Strategies for qualitative inquiry (2nd ed.) (pp. 134-164). Thousand Oaks, CA: Sage.

Tinto, V. (1993). Leaving college: Rethinking the causes and cures of student attrition (2nd ed.). Chicago, IL: University of Chicago Press.

Watts, J. H. (2008). Challenges of supervising part-time PhD students: Towards student-centered practice. Teaching in Higher Education, 13(3), 369-373.

Weidman, J. C., Twale, D. J., \& Stein, E. L. (2001). Socialization of graduate and professional students in higher education: A perilous passage? San Francisco, CA: Jossey Bass.

Wenger, E. (1998). Communities of practice: Learning, meaning, and identity. New York, NY: Cambridge University Press.

White, J., \& Nonnamaker, J. (2008). Belonging and mattering: How science doctoral students experience community. NASPA Journal, 45(3), 350-372.

Woodrow Wilson National Fellowship Foundation. (2005). The responsive PhD. Retrieved November 27, 2011 from http://www.woodrow.org/responsivephd/conference.php

Yin, R. K. (2012). Applications of case study research (3rd ed.). Thousand Oaks, CA: Sage. 


\section{Appendix A \\ Interview Protocol for Department Chairs}

Introduce self and review the Study Information Sheet with the partici-

pant. Advise that the interview will take 60 to 90 minutes.

Interview Questions:

1. Tell me about the Ph.D. program in (depart-

ment/program name). Potential probes:

a. Program/Chair/Coordinator's role in the program

b. Number of students, part-time vs. full-time numbers

c. Number of faculty, faculty involvement in Ph.D. program

d. Activities, resources, supports for Ph.D. students

2. Tell me about a typical day in your academic department. What types of things happen there? Potential probes:

a. Student interactions with faculty inside the classroom? Outside the classroom?

b. Student interactions with peers inside the classroom? Outside the classroom?

c. Interactions with student services staff?

d. Do you believe students feel a sense of connection to the faculty and peers in your academic department? Why/why not?

3. How do you define a sense of community within an academic department? Potential probes:

a. What do you think students look for in the departmental environment?

b. Do you feel that there is a sense of community here, the way you just described it?

c. What role should the program department have to foster a sense of community?

4. What do you think motivates students to continue in the program each semester? Potential probe:

a. What recommendations would you share with part-time doctoral students to help them be successful?

5. Do you think there are differences in the experiences of part-time students vs. full-time students?

6. Are there any other important things for me to know about this Ph.D. program? 


\section{Appendix B \\ Interview Protocol for Student Participants}

Introduce self and review the Study Information Sheet with the participant. Advise that the interview will take 60 to 90 minutes.

Interview Questions:

1. Tell me about yourself before you entered your doctoral program.

2. What factors and/or experiences in your life brought you here? Potential probes:

a. Family, relationships, previous experiences

b. Motivation

3. What factors influenced your decision to pursue your Ph.D. program on a part-time basis?

4. What expectations did you have of your doctoral program? Potential probes:

a. Who discouraged/encouraged you, if anyone?

b. Have your experiences differed from your expectations? If so, in what ways?

c. Have your relationships changed since being a doctoral student?

5. When you arrived on campus, what were your initial impressions about the academic department? Potential probes:

a. Impressions about the faculty and staff?

b. Impressions about the students?

6. Tell me about your personal support system. Potential probes:

a. Family, friends, others...

b. What role do they play in your life?

7. Tell me about a typical day in your academic department. What types of things do you do and see there? Potential probes:

a. Interactions with faculty inside the classroom? Outside the classroom?

b. Interactions with students inside the classroom? Outside the classroom?

c. Interactions with university administrative staff and student services staff?

d. Do you feel a sense of connection to the faculty and peers in your academic department? Why/why not?

8. How do you define a sense of community within your world as a doctoral student? Potential probes:

a. What would you look for in the departmental environment?

b. Do you feel that you are part of a community, the way you just described it?

c. Do you feel that you have to go out of your way to develop relationships with peers and faculty?

d. What role should the program department have to foster a sense of community?

9. Talk about how you balance coursework, work, personal commitments, etc.?

Potential probes:

a. How did your other roles impact your role as a student? 
10. What motivated you to continue in your program each semester? Potential probes:

a. Was there a time when you considered leaving your doctoral program?

b. What strategies did you use to continue through your program?

11. Do you think there are differences in the experiences of part-time students vs. fulltime students?

12. What recommendations would you share with other part-time doctoral students to help them be successful?

13. Are there any other important things for me to know about your experiences as a parttime doctoral student?

\section{Biography}

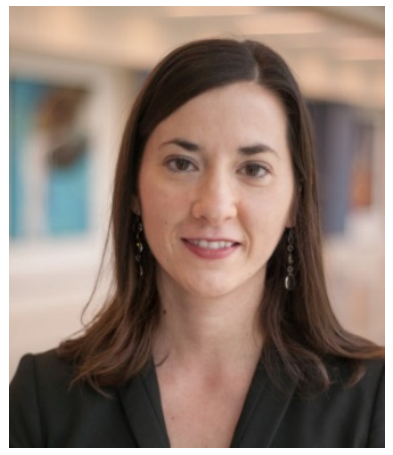

Sarah B. Zahl, Ph.D., is the Director of Educational Assessment, Assistant Professor of Family Medicine, and Assistant Professor of Education at Marian University in Indianapolis, Indiana. Dr. Zahl earned her Ph.D. and M.S. in Higher Education from Indiana University and a B.S. degree in Journalism from Butler University.

In addition to her administrative roles, she has taught courses in Education, Qualitative and Quantitative Research Methods, and College Teaching and Learning. She has ten years of experience in academic and student affairs in higher education.

Dr. Zahl has presented her work at national and international conferences and has earned grants, awards, and fellowships for her scholarship and practice. Her academic interests include tracking student success factors during graduate study, competency based assessment, and mapping the curriculum. 